\title{
Community-based early warning systems for flood risk mitigation in Nepal
}

\author{
Paul J. Smith ${ }^{1}$, Sarah Brown ${ }^{2}$, and Sumit Dugar ${ }^{3}$ \\ ${ }^{1}$ Lancaster Environment Centre, Lancaster University, Lancaster, UK \\ ${ }^{2}$ Practical Action Consulting, Rugby, UK \\ ${ }^{3}$ Practical Action Consulting, Kathmandu, Nepal \\ Correspondence to: Paul J. Smith (paul@waternumbers.co.uk)
}

Received: 1 April 2016 - Discussion started: 15 April 2016

Revised: 16 October 2016 - Accepted: 27 October 2016 - Published: 20 March 2017

\begin{abstract}
This paper focuses on the use of community-based early warning systems for flood resilience in Nepal. The first part of the work outlines the evolution and current status of these community-based systems, highlighting the limited lead times currently available for early warning. The second part of the paper focuses on the development of a robust operational flood forecasting methodology for use by the Nepal Department of Hydrology and Meteorology (DHM) to enhance early warning lead times. The methodology uses databased physically interpretable time series models and data assimilation to generate probabilistic forecasts, which are presented in a simple visual tool. The approach is designed to work in situations of limited data availability with an emphasis on sustainability and appropriate technology. The successful application of the forecast methodology to the floodprone Karnali River basin in western Nepal is outlined, increasing lead times from $2-3$ to $7-8 \mathrm{~h}$. The challenges faced in communicating probabilistic forecasts to the last mile of the existing community-based early warning systems across Nepal is discussed. The paper concludes with an assessment of the applicability of this approach in basins and countries beyond Karnali and Nepal and an overview of key lessons learnt from this initiative.
\end{abstract}

\section{Introduction}

Nepal is considered one of the most disaster-prone countries in the world (NRRC, 2011). Alongside other natural hazards, such as earthquakes and landslides, flooding poses a recurrent risk to large sections of the population. Between 1971 and 2011, 3520 flood events were recorded, causing 3329 deaths and affecting 3.9 million people (DesInventar, 2015).

Detailed analysis of two recent flood events, the 1993 central Nepal floods (NCVST, 2009), and the Koshi embankment breach in 2008 (Dixit, 2009) highlights the extent to which vulnerability contributes to flood risk. Vulnerability stems from multiple sources (Khanal et al., 2015) but is increased by poor disaster preparedness and risk management on both the individual and institutional levels. Section 2 outlines in more detail the nature of the flood risk in a major river basin in Nepal, the Karnali River basin.

Improving the flood resilience of communities and infrastructure in Nepal is a priority for the national government (NRRC, 2011; MoHA, 2015) and the international community. This has led to various initiatives, such as the World Bank funded "Building Resilience to Climate Related Hazards" programme (http://brch.dhm.gov.np/), and engagement from regional institutions such as the "Regional Integrated Multi-Hazard Early Warning System for Africa and Asia" (RIMES, http://www.rimes.int). Both of these initiatives collaborate with the government of Nepal, particularly the Department of Hydrology and Meteorology, to build institutional capacity for anticipating future floods through activities such as expanding the hydrological and meteorological station network or developing prototype forecasting systems.

An approach to improving flood resilience, the development of which has been supported by international non-governmental organizations (INGOs), is the use of community-based early warning systems (CBEWSs). A CBEWS is an early warning system (EWS) where communities are active participants in the design, monitoring and 
management of the EWS, not just passive recipients of warnings. Community-based flood early warning systems are in place in a wide range of countries, for example in Malawi with support from Christian Aid (Brown, 2014), in Indonesia (e.g. in the Binajaan basin Practical Action and Mercy Corps, 2012) and in Cambodia (Kandal Province) with support from the national societies Red Cross and Red Crescent (IFRC, 2010). In 2002, Practical Action piloted a CBEWS for floods in the East Rapti-Narayani river basin in Nepal and has since expanded CBEWS into a wide number of other basins in and beyond Nepal, including the Karnali River basin (Shukla and Mall, 2016; Practical Action and Mercy Corps, 2012).

Section 3 outlines the evolution, current status and ongoing limitations of CBEWSs in Nepal, focusing on the Karnali River basin. While successful at saving lives, the often limited lead time (2-3h in the Karnali River basin) means that CBEWSs may not be adequate for saving assets or livelihoods (Zurich, 2015). Increasing the lead time, hence the time available for action (while maintaining the accuracy and precision of the warning), would allow for a more proactive response to flood risk. To this end, Sect. 4 outlines the desirable properties of a forecasting system designed to enhance CBEWSs within Nepal. Section 5 presents a robust operational flood forecasting system developed in response to these requirements. Results from an experimental application in the flood-prone Karnali River basin in western Nepal are given in Sect. 6. Section 7 discusses ongoing pilot studies incorporating forecasts of the type outlined into CBEWSs. The conclusions (Sect. 8) summarize the key lessons that can be drawn from this initiative.

\section{Flood risk in Nepal}

Nepal is bordered by the Himalayas in the north and the Indian plains to the south (Shrestha et al., 2008). The country has a diverse topography, which can be classified into five physiographic zones extending from the east to the west of the country (NCVST, 2009). From south to north these are the Terai plains, Siwalik Hills, the Middle Hills, the High Mountains and the High Himalayas (Zurich, 2015).

Figure 1 shows the main rivers in Nepal. There are major snow-fed rivers, such as the Koshi, Gandaki, Karnali and Mahakali, along with mid-size rain-fed rivers such as Mechi, Kankai, Bagmati, East Rapti, West Rapti and Babai. In addition, there are intermittent rivers originating from the Siwalik Hills that are subject to frequent flash floods and carry high sediment loads (Sharma, 1997), despite having no significant flow outside of the monsoon season.

The Karnali River basin lies in western Nepal (see Fig. 1). The Karnali River is a perennial transboundary river that originates in the Himalayas. It has three main tributaries (West Seti, Bheri and Karnali), which drain an area of $45000 \mathrm{~km}^{2}$ above the Chisapani gauge station (Zurich, 2015). The Chisapani gauge station marks the boundary be-

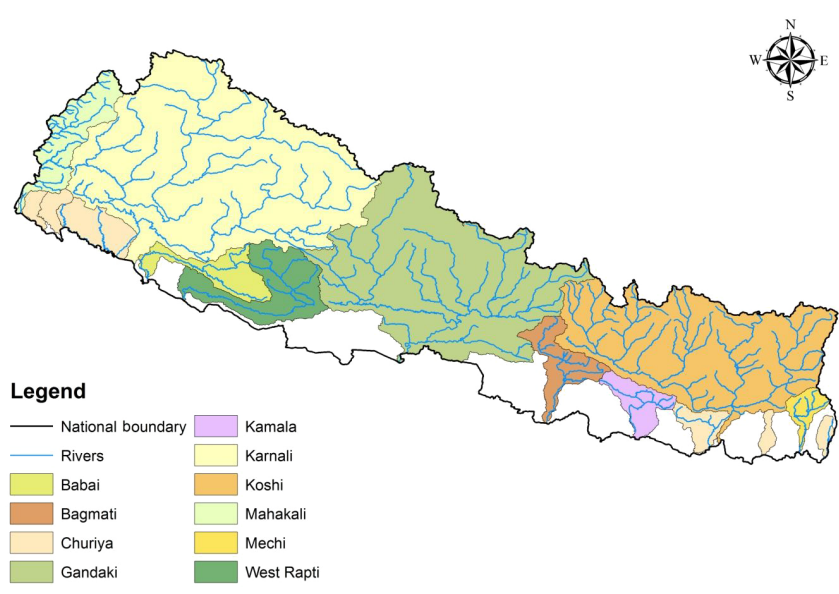

Figure 1. Map of Nepal showing the major river basins.

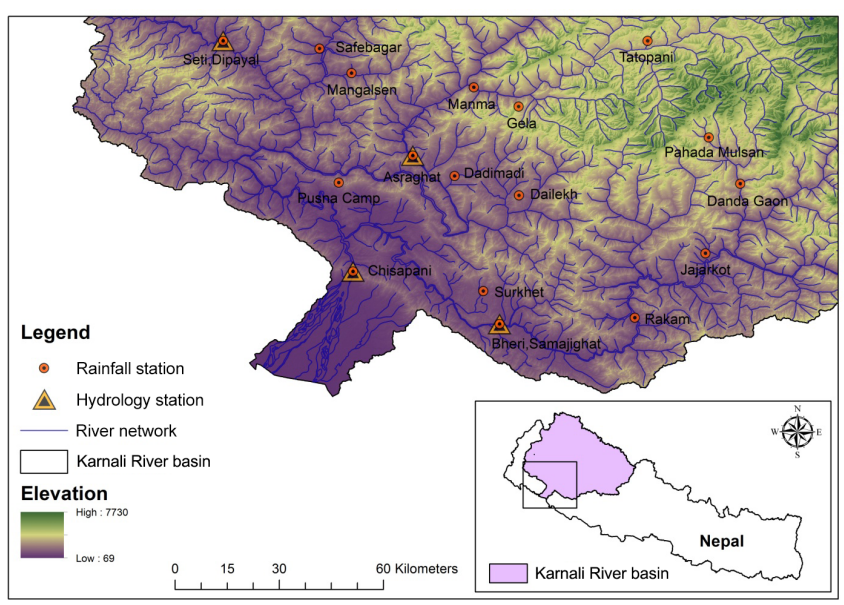

Figure 2. Detailed map of the Karnali River basin, including topographic detail and the location of monitoring stations within the catchment.

tween the upper catchment dominated by steep-sided mountainous valleys and the lower catchment consisting of a flood plain that runs to the Indian border (Fig. 2).

The climatic regime of the Karnali River basin is affected by the monsoon (June-September) and westerly circulation systems, with the former being dominant (Gautam and Phaiju, 2013). Analysing the historical records made available by the Nepal Department of Hydrology and Meteorology (DHM) indicates that the $70-80 \%$ of the annual total precipitation and river flow occurs during the monsoon (Gautam and Phaiju, 2013; Shrestha et al., 2014). Snow melt contributes to pre-monsoon and post-monsoon stream flow. The concentrated period of high rainfall results in dramatic changes in flow and water level from summer to winter. For example, the changes in water level shown in Fig. 3 represent a change in discharge from around 500 to $10000 \mathrm{~m}^{3} \mathrm{~s}^{-1}$.

Despite the strong seasonal pattern in river flows in the Karnali River basin, forecasting is still challenging. During 


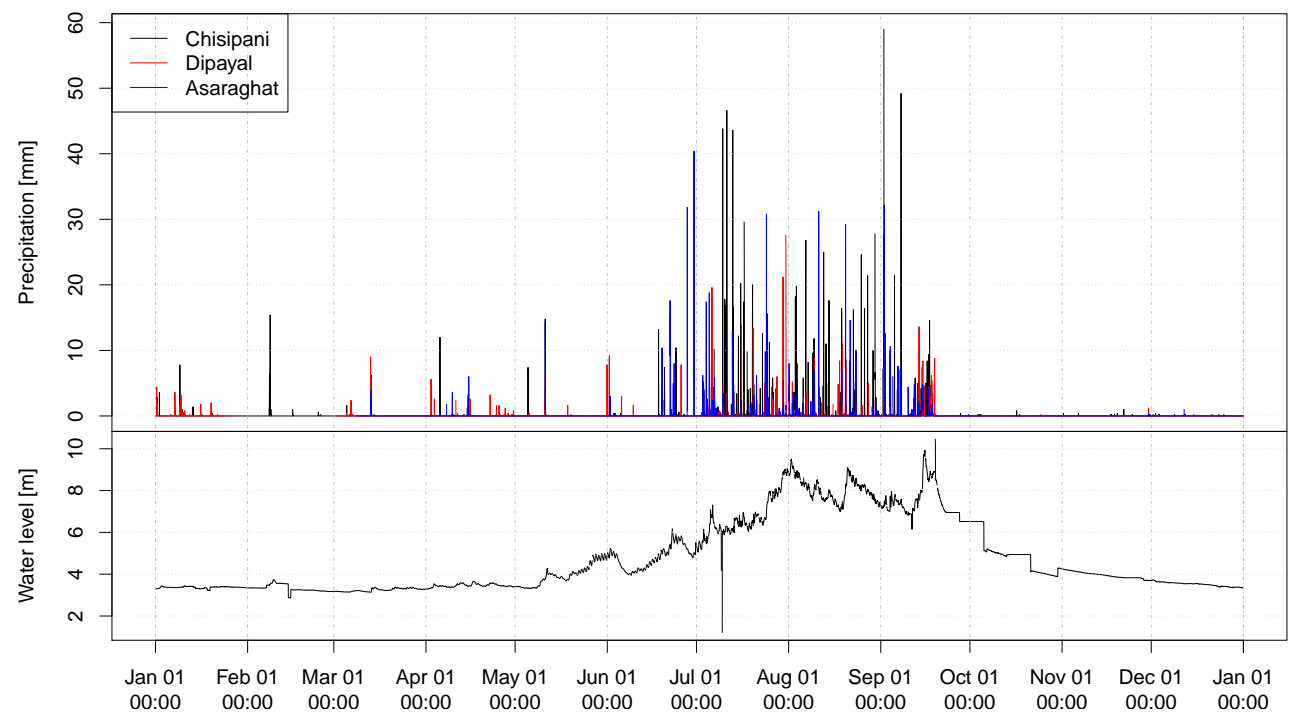

Figure 3. An example year of data for the Karnali River basin showing the observed water level at Chisapani (lower pane) and rainfall recorded at the three gauges (Chisapani, Dipayal and Asaraghat). Note the spatial variability in the rainfall and, even in this comparatively dry monsoon, the river range of approximately $7 \mathrm{~m}$.

the monsoon there is a high variability in magnitude, duration and intensity of precipitation at the macro- and micro-scales (NCVST, 2009). Assessing the impact of this is problematic due to limited understanding of the response of river flow to the high intensity and short duration precipitation events, which trigger floods downstream (Shrestha et al., 2008). The production of forecasts is further complicated by Nepal's dynamic geomorphology coupled with topographic and geological constraints, which makes the collection of reliable data difficult (Nepal et al., 2014).

Significant flood events have occurred in the Karnali River basin in 1983, 2009, 2013 and most recently 2014 (Zurich, 2015). In the Karnali River basin, as with other basins in Nepal, flooding has a particular impact on communities residing in the Terai (NCVST, 2009), affecting livelihoods and especially affecting subsistence agriculture in the floodplains (Zurich, 2015). Floods kill livestock, which is of critical importance to poor communities, with 14571 cows, pigs, chickens and goats killed in the 2008 Koshi flood (Baral, 2009). Floods also deposit sand on farmland, negatively affecting agricultural livelihoods and food production (Gautam and Dulal, 2013). As well as damage to lives, livelihoods and property, floods damage critical roads, communication infrastructure and power supplies, significantly impacting development (Gautam and Dulal, 2013).

In the Karnali River basin, a CBEWS has been successfully operating (in the lower catchment, which lies on the Terai) since 2010. This CBEWS has been initiated by the INGO Practical Action working alongside the DHM. Section 3 provides further details on the CBEWS in Karnali.

\section{Community-based early warning systems}

Early warning systems (EWSs) are defined as "the set of capacities needed to generate and disseminate timely and meaningful warning information to enable those threatened by a hazard to prepare and act appropriately and in sufficient time to reduce the possibility of harm or loss" (UNISDR, 2006). Early warning is a key component of disaster risk reduction. Enhancement of risk monitoring and early warning is the second priority of the Hyogo Framework for Action 2005-2015 (UN, 2005) and a key component of the current Sendai Framework for Action 2015-2030 (UN, 2015).

The Hyogo Framework prioritized the development of people-centred early warning systems encompassing four critical components: risk knowledge, monitoring and warning, dissemination and communication and response capability (UNISDR, 2006; UN, 2005; IFRC, 2010). Effective EWSs provide warnings that are accurate, timely and understandable, enabling at-risk groups to respond appropriately (Shrestha et al., 2014). Weakness in any of the four key areas can result in EWS failure (UNISDR, 2006; Kundzewicz, 2013).

Community-based early warning systems (CBEWSs), such as those outlined in this paper, are people centric, helping communities use local resources and capacities to effectively prepare for and respond to flood events. This enables communities to reduce their vulnerability to flood risks (Mercy Corps and Practical Action, 2010). In a CBEWS the communities are active participants not just in the design but also in the ongoing monitoring and management. As outlined in the remainder of this section, community involvement at all levels in CBEWSs often entails an emphasis on 
end-mile dissemination and the use of sustainable and appropriate technology.

\subsection{Community-based early warning systems (CBEWSs) in Nepal}

The first CBEWS in Nepal was piloted by the INGO Practical Action in 2002 for the East Rapti River (Practical Action, 2008). This initial pilot was enhanced and extended, expanding over the next 10 years to cover eight river basins across Nepal (Karnali, West Rapti, Babai, East Rapti, Narayani, Bagmati, Kankai and Koshi basins) (Gautam and Phaiju, 2013). Over the past 5 years, the CBEWSs have become increasingly integrated with EWS provided by the national government, whilst maintaining community driven and managed features.

This section will focus on the CBEWS in place in one major river basin, the Karnali River basin in western Nepal. The Karnali CBEWS considers all four key EWS components listed in the Hyogo framework (risk knowledge, monitoring and warning, dissemination and communication, and response capability), as will be outlined below.

\subsubsection{Risk knowledge}

Risk knowledge involves assessing and mapping key hazards, vulnerabilities and exposure (UNISDR, 2005). At the community level, this information can be discussed and documented through Community Risk Assessments (IFRC, 2012) such as Participatory Vulnerability and Capacity Assessments (PVCAs). In a CBEWS an emphasis is placed on community actors having awareness and understanding of risk (vulnerability, capabilities, exposure and hazards) (IFRC, 2010; Mercy Corps and Practical Action, 2010). Early CBEWSs in Karnali worked directly with communities to map historic flood events and to determine the relationship between observed river height at an upstream location and expected inundation downstream. Upstream "warning" and "danger" water levels were then established based on past floods (Gautam and Phaiju, 2013). Later CBEWSs in Karnali derived these thresholds at a community level based on a mixture of flood hazard mapping (carried out by DHM) and community experience.

For Karnali, warning and danger levels of the river height at Chisapani gauge station (upstream of flood-vulnerable communities) were calculated to correspond to expected river height in downstream communities. The danger and warning levels at the Chisapani gauge station are intended to correspond to

- Warning Level - condition when water reaches the top of the riverbanks for the downstream site at risk,

- Danger Level - condition when water overflows the riverbanks and water enters the communities and floodplains downstream.
Communities also identify safe locations and routes that can be used for evacuation during floods via participatory methods. These exercises combine scientific and community knowledge to help communities gain a better understanding of flood risk and take necessary steps during a flood event.

An acknowledged challenge is ensuring that the applied danger and warning levels continue to correspond to the actual impact. This is a significant concern in an area like the Karnali River basin, where the area at risk is a low-lying inland delta with wide, shallow, naturally mobile channels. These display significant sediment movement and braiding and are subject to time varying human impact (irrigation channels being cut, banks eroded due to vehicular river crossing at low flows, etc.). In such an environment the accurate spatial prediction of impacts is (at least) very challenging and subject to significant uncertainties. Key to the success of the CBEWS is the recognition of this and an acceptance that community input is required in both the initial setting and the ongoing revision of the levels used to trigger alerts and warnings.

\subsubsection{Monitoring and warning}

EWSs require a monitoring and warning component, including hazard monitoring, defining parameters and indicators on which to base early warning, and ensuring accurate and timely forecasts and alerts (UNISDR, 2005). In CBEWSs communities are the active owners and drivers of their EWS, engaged in monitoring and or analysis, rather than passive receivers of early warning (IFRC, 2012).

Initially the CBEWSs trained community gauge readers to monitor river levels and disseminate warnings to downstream communities when river levels rose above the defined warning and danger thresholds (Mercy Corps and Practical Action, 2010). Currently, in addition to the rising water level, gauge readers also disseminate warnings when the observed rainfall in the upstream catchment exceeds certain thresholds that might trigger floods downstream. Community level structures, such as Community Disaster Management Committees (CDMCs), also monitor and record information on flood levels, duration and impact (Gautam and Phaiju, 2013).

Over the past decade, in close partnership with the DHM, these community systems of manual river-gauge monitoring have evolved to become integrated with national systems (Practical Action and Mercy Corps, 2012). DHM now has 286 meteorological and 170 hydrological stations nationwide (Shrestha et al., 2014). Most of these stations are manually operated, though some have been upgraded to automatic stations, with continuous monitoring of water level and/or rainfall. In the Karnali River basin, there are 7 hydrological and 25 rainfall stations that are fully automated, along with a combined station at Chisapani.

River gauges in Nepal are maintained by the government via part-time staff who, in nearly all cases, are members of the local community who are trained to record and monitor 
river water levels. This results in a situation where, although the government pays for the gauges, information on water levels (in the period immediately leading up to flooding) is provided directly to the local community by one of its members.

The automated gauge network links to a national-level DHM-managed web-based flood early warning system, which monitors rainfall and river height, with real-time data publicly accessible through the DHM website (Shrestha et al., 2014). Data is transmitted to the DHM server every $15 \mathrm{~min}$, with flood warning bulletins available on www. hydrology.gov.np throughout the monsoon period (Gautam and Phaiju, 2013).

\subsubsection{Dissemination and communication}

Once a warning or danger level is reached, the dissemination and communication components of an EWS are critical. Dissemination and communication focuses on whether warnings reach all "at-risk" groups, whether such warnings are understood and if they are acted upon (UNISDR, 2005). Effective early warning messages convey timing (when the hazard is due to strike), location, scale, impact (what will be the effect on at risk groups), probability and response (what should at-risk populations do to protect themselves) (IFRC, 2012). Systems are put into place and tested to ensure that the early warning is disseminated widely and in a timely and efficient manner (WMO, 2015). "An actionable early warning provides a timely message that reaches, is understood and is acted upon by the population at-risk" (IFRC, 2012).

Work with the CBEWS in Karnali has focused on building redundancy into early warning dissemination avoiding a "singular dependence on one communication device or channel" (IFRC, 2012). In Karnali, gauge readers disseminate warnings via mobile telephones and SMS using predefined communication charts (Mercy Corps and Practical Action, 2010). These communication charts have the contact details of all relevant stakeholders and dissemination procedures and protocols that are prepared in advance and updated regularly before each monsoon (Shrestha et al., 2014). Through these channels, information regarding preparation for floods, mobile numbers of upstream gauge readers and actions to be taken during floods are disseminated as well as the actual warnings.

Amongst those informed by the gauge readers are the District Disaster Relief Committees (DDRCs), District Emergency Operation Centre (DEOC), Community Disaster Management Committee (CDMC) members, security forces (police and army) and local media, enabling wider dissemination (Zurich, 2015).

Dissemination of warnings initiated by the gauge readers can be seen as "bottom up", starting at the most local level. Two "top-down" dissemination routes also exist, both based on the automated network of river gauges. The first of these occurs at the sub-national level where district-level government offices maintain electronic flood monitoring display boards with sirens that sound automatically when water reaches warning levels.

The second utilizes the telemetry system to trigger automatic SMS text messages, such that warnings are sent to chief district officers, DHM basin offices, along with security forces (Gautam and Phaiju, 2013). The chief district officer simultaneously mandates security forces to communicate warnings to police posts, army posts and local FM radio stations to enable wider community dissemination (Gautam and Phaiju, 2013).

Once warnings reach communities, Community Disaster Management Committees (CDMCs) come into action and, using handheld megaphones, loud speakers and sirens, make sure the warning reaches all community members. Various community task forces such as first-aid and search and rescue are called into action, ensuring all at-risk groups, particularly groups of higher vulnerability, are informed and assisted when responding or evacuating to safer locations (Shrestha et al., 2014).

\subsubsection{Response capability}

Response capability focuses on building local and national capacities to respond appropriately to early warnings by putting into place well-defined response plans whilst building upon local capacities and knowledge (UNISDR, 2005). Actions focus on strengthening the "capacity of at-risk communities and volunteers to receive, analyse and act on warnings" (IFRC, 2012).

Awareness-raising programmes in the Karnali River basin have used a wide range of approaches. These range from disseminating messages via FM radio, to posters, calendars, leaflets, wall paintings, song competitions, street theatre, and school art and essay competitions, all conveying key information to support appropriate preparedness and reaction to early warnings (Gautam and Phaiju, 2013).

Response capabilities have been strengthened by predefining response options, roles and responsibilities (including identifying evacuation routes and safe areas), ensuring teams have access to dissemination and response materials (e.g. loud speakers, life vests, rope) and embedding response plans in wider contingency plans that coordinate across multiple local and national levels (Mercy Corps and Practical Action, 2010). Individuals designated as "first receivers" of early warning messages can be trained in interpreting, repackaging and communicating such messages to ensure they are disseminated in a manner appropriate to each target group (IFRC, 2012).

Response capabilities are also enhanced through practising and testing response plans through mock drills and undertaking post-event reviews to learn from past hazard events (WMO, 2015). 'A community is deemed 'response capable' when they know, have practised and have the means to engage in appropriate response actions" (IFRC, 2012). These 
response capabilities are generally put to test during a flood event, and any shortcomings are discussed during PVCA assessments and CDMC meetings to ensure enhanced response to the next monsoon.

\subsubsection{Successes and limitations}

Prior to 2002 and the first CBEWS in the East Rapti River basin, there were no operational forecasting and early warning systems in place in Nepal and therefore no coordinated early warnings, evacuations or early responses. The effectiveness of CBEWSs in Nepal has been demonstrated on a number of occasions, including during the 2010 monsoon in Banke District (Mid-Western Region, Nepal), where the district gauge reader upstream informed downstream communities of rising water levels, enabling the safe evacuation of flood-prone communities in Binauna.

The CBEWSs in the Karnali River basin give vulnerable communities around 2-3h of lead time to prepare in the event of a flood (Practical Action and Mercy Corps, 2012). In the 2014 floods in West Nepal, CBEWS worked effectively in the Karnali and West Rapti river basins, where communities received flood warnings and were able to respond effectively and in time.

Tragically in 2014 the CBEWS did not succeed in the nearby Babai River basin and lives were lost (Zurich, 2015). The failure of the CBEWS in Babai was primarily due to the washing away of the water level gauging station used for triggering alerts. Communities and stakeholders downstream were thus deprived of critical information regarding when water levels crossed the warning and danger thresholds. Compounding this, the gauge reader was unable to access the gauge station to provide a manual assessment of the flows (he was trapped between torrents of water in the trail leading to the station) and damaged his cell phone. This left him unable to communicate with local communities, security forces and district authorities at a crucial period. The resulting delays in the response and rescue operations contributed to more than 20 people losing their lives. A further contributing factor was that floodwaters entered places that were deemed safe in past risk mapping exercises and caught communities by surprise.

Three significant limitations of the current early warning system based on monitoring river levels have been identified. Firstly, the current system is reliant on real-time water level readings, yet both automatic and manual systems are susceptible to failure during extreme rainfall events (as in Babai where the hydro-met station was washed away) (Zurich, 2015). Secondly, lead times are short, especially where rivers convey water rapidly, a common situation in mountainous catchments. Thirdly, Nepal has a limited density of hydro-met stations, particularly in remote or hard-toaccess areas, meaning some flood-prone areas do not have a corresponding upstream gauge (Zurich, 2015).
The current CBEWS in Karnali offers $2-3 \mathrm{~h}$ of warning time to downstream communities at risk of flooding. The current, very limited lead time for early warnings are sufficient for saving lives, but an extended lead time will offer a number of potential benefits:

- Extended lead times allow for a more robust system of early warning; currently any failure in communication results in a delay that may render the warning ineffective.

- Current lead times are insufficient for saving movable assets, livestock, livelihood tools, etc. Warnings with extended lead times could help protect livelihoods as well as lives.

- Adding to the warning lead time would enhance the confidence in this system reaching all at-risk groups.

- A 2-3 h lead time for evacuation is especially challenging for vulnerable groups, such as disabled people, pregnant women, the elderly, and children. Increasing the lead time enables safer evacuation.

The last significant flood event in the Karnali River basin (2014) released a warning at 13:00 LT (all times are local time) at a time when most people were asleep and the river was high and rising quickly, with evacuation occurring during dangerous conditions in the dark in the early hours of the morning. Increasing the lead time gives more likelihood of warning messages being transferred and evacuation occurring when communities are awake and/or during daylight hours and before river conditions are at their worst, enabling safer and easier evacuation. An increased lead time would also enable a warning to be released before river levels are at the danger level, enabling warning before critical gauges and monitoring stations are likely to be damaged or washed away by the flood, increasing the robustness of the EWS.

\section{Forecasting for CBEWS}

Hydrological forecasts can be used to predict future water levels, expanding the lead time of an EWS based on monitoring river levels. Smith et al. (2013) identify two distinct horizons for hydrological forecasts. The first horizon of days or weeks relies on numerical weather prediction and is useful for strategic activities such as recovery planning. The second forecast horizon, often of the order of hours, is required to communicate urgent warnings to local communities, and is therefore of more direct benefit in augmenting CBEWS.

A common approach (Cloke and Pappenberger, 2009) to generating forecasts at either horizon is to cascade meteorological forecasts through a hydrological model, resulting in predictions of discharge that can be related to the water level threshold used to issue warnings. Existing global or local area numerical weather prediction (NWP) models could be 
used to provide meteorological forecast data. The resolution and performance of such precipitation forecasts is, however, inadequate for the shorter forecast horizons, which best complement the existing CBEWS (Regmi et al., 2011). Moreover, suitable hydrological models do not exist for many major river basins in Nepal, including the Karnali.

In addressing these problems to develop a forecasting methodology, importance was placed on the sustainability and technological appropriateness of the solution. Desirable features of a suitable approach would include

- near zero running and setup costs, including licenses and hardware provision;

- a simple and transferable means of interfacing with existing CBEWS infrastructure, including data collection, warning levels and dissemination mechanisms;

- open and well-documented code that can be maintained and developed with limited ongoing external support and restrictions;

- limited or no reliance on external data sources that may become unavailable.

Section 5 outlines one solution that meets these requirements predicting future values of the observed water level using only the available observed rainfall data as an input. In Sect. 6 it is demonstrated that such an approach can offer forecasts of adequate lead time to enhance the existing CBEWS in the Karnali basin.

\section{Data-based mechanistic modelling}

The forecasting methodology developed to align with the CBEWS uses a data-based mechanistic (DBM) modelling approach (Young, 2002) to predict future water levels at a site where CBEWS warning thresholds are defined. In this approach each gauged site where warning thresholds are defined requires its own model.

As in previous works using DBM modelling (see Alfieri et al., 2011; Beven et al., 2011; Leedal et al., 2013; Romanowicz et al., 2008, and the references below) the focus is on forecasting water levels. This removes the effects of the uncertainties in the rating curve used to compute discharge from the observed water level. Such models cannot be constrained by mass balance. This may be advantageous for flood forecasting, where a knowledge of rainfall input data may be limited and rating curves extrapolated well beyond the range of available measurements.

The data-based mechanistic modelling approach is based on the estimation from observed data of parsimonious time series models that can be interpreted in a hydrological fashion (see for example Young and Beven, 1994; Young, 2002, 2003; Smith et al., 2013). Section 5.1 outlines the application

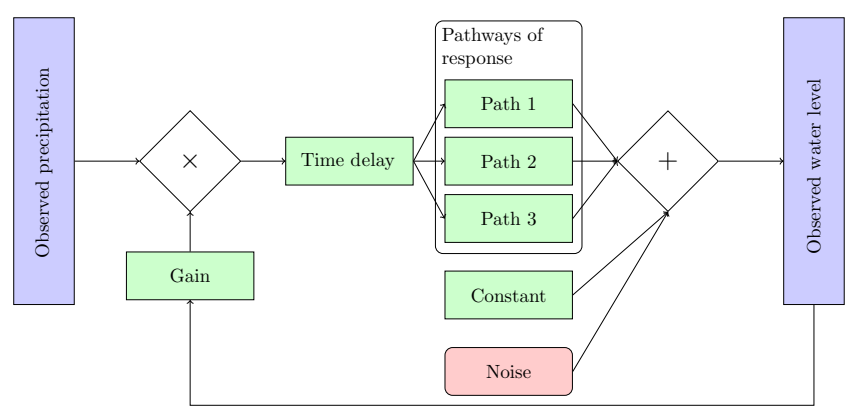

Figure 4. Schematic representation of a simplified DBM model showing the relationship between input precipitation, gain, linear pathways of response, a constant minimum water level and noise that gives the observed water level.

of the DBM approach developed to support CBEWS and applied in the Karnali River basin. This is a simplification of the more general approach used in previous work. The simplifications enforce a specific hydrological interpretation of the resulting models, which is motivated by the findings presented in Smith et al. (2013) (see also Romanowicz et al., 2006, 2008; Beven et al., 2011, and the references within).

It has been widely recognized by both scientists and users (Penning-Rowsell et al., 2008; Frewer et al., 1996) that the uncertainty in the forecasts should be recognized and if possible quantified. As outlined in Sect. 5.3 the structure of the models that result from the DBM approach are well suited to the assimilation of real-time water level data to reduce the uncertainty in the forecasts, which can then be quantified.

Further details of the DBM techniques used can be found in Smith (2017a), which outlines FloodForT, the software package developed by the authors in the R statistical computing language (Ihaka and Gentleman, 1996) to implement the methodology and provide a convenient web-based graphical user interface (GUI). Both are available by request from the corresponding author.

\subsection{Simplified DBM forecast models}

Each model represents the hydrological response in the form of the water level at a single gauge using a single input series. In the description below this is taken to be a catchment average precipitation estimate derived from the weighted average of rain gauge observations, but it could in certain situations be an observed upstream water level series.

The model formulation shown in Fig. 4 indicates that the observed output is modelled as the summation of three components:

1. a constant that is set at a value indicative of the water level during long dry periods,

2. a non-linear response to the rainfall,

3. a stochastic noise with unknown statistical properties. 
The non-linear response to the rainfall is formed by three components. The first of these is a non-linear transformation of the observed rainfall to an effective value. This is achieved at each time step of model evaluation $t$ by multiplying the observed rainfall $\left(u_{t}\right)$ by a gain value $\left(f_{t}\right)$ to give an effective input $\left(f_{t} u_{t}\right)$. In the case of a rainfall input the value of the gain relates to wetness of the catchment, with wetter catchments typically producing more of a response to rainfall. A number of different methods to calculate the gain have proved acceptable representations of a variety of catchments (see for example, Beven et al., 2011; Romanowicz et al., 2006, 2008; Leedal et al., 2013). In the work on the Karnali River basin three representations of the gain are used. The first is that with a lack of non-linearity, where the gain takes a constant value of 1 . In the remaining two parametric representations, the gain $\left(f_{t}\right)$ is related to the observed water level at the same time step $\left(y_{t}\right)$, which is used as a surrogate for catchment wetness. The second representation is the widely used power law non-linearity, where $f_{t}=y_{t}^{\phi}: 0<\phi<1$. The constraints on $\phi$ ensure that $f_{t}$ is strictly increasing as $y_{t}$ increases but asymptotes to a constant value, indicating a saturated catchment.

The final parametric description of the input non-linearity available is a sigmoid where

$$
f_{t}=\frac{1}{1+\exp \left(-\phi_{1}\left(y_{t}-\phi_{2}\right)\right)},
$$

which is strictly increasing if $\phi_{1}>0$. The additional flexibility offered by this functional form allows for greater flexibility in the location of the most rapid change in $f_{t}$. This can be useful in representing catchments where there may be a distinct "wetting up" phase before parts of the catchment produce a significant response to the input.

The observed value of the water level can be used in computing the gain series due to the time delay component in the response to the effective rainfall. This is considered to be a pure time delay. If the time delay is $d$ time steps, the input to the final components, the linear pathways of response, is the effective rainfall computed $d$ time step before $\left(f_{t-d} u_{t-d}\right)$. Due to this, the maximum lead time of the model is $d$ time steps.

The final components of the non-linear response to the rainfall are the parallel linear pathways of response. Each of these is a linear transfer function where the output of the $i$ th pathway at time $t$, denoted $y_{t, i}$, is constant fraction $\alpha_{i}$ of the value at the previous time step added to a product of a constant $\beta_{i}$ and the delayed input $\left(f_{t-d}, u_{t-d}\right)$ as shown in Eq. (2).

$y_{t, i}=\alpha_{i} y_{t-1, i}+\beta_{i} f_{t-d} u_{t-d}$

To ensure that the response, a linear pathway, decreases when there is no effective rainfall and increases with effective rainfall the following parameter restrictions are applied to all paths:

$0<\alpha_{i}<1$,

$0<\beta_{i}$.

\subsection{Identification and estimation of the model}

The simplified DBM model outlined in Sect. 5.1 results, for each model structure defined by a combination of nonlinearity, time delay $(d)$ and number of pathways of response $(n)$, in a vector of parameters $\theta=\left(\alpha_{1}, \ldots \alpha_{n}, \beta_{1}, \ldots \beta_{n}, \phi\right)$, which require estimation. This is achieved using a generalized method of moments (GMM, Hall and Inoue, 2003) methodology, which is in keeping with the methods outlined in Beven et al. (2011) and used in, for example, Leedal et al. (2013). A robust estimate of $\Sigma$, the covariance of the estimate of $\theta$, is provided by the heteroscedastic autocovariance consistent (HAC) estimator of Newey and West (1987).

Since the estimation of parameter vector is rapid, an exhaustive search of the combinations of model non-linearity, $n$ and $d$, is performed. For each estimated model, a number of summary statistics (Table 1) are produced. Those that trade off model fit and parsimony, such as the Young Information Criterion (YIC, Young and Beven, 1994), can then be screened to remove poor or over-parameterized models. Those that remain can undergo a more detailed analysis using, for example, the threshold RMSE and visual inspection of the model hydrographs (particularly focusing on the timing of the rising limbs) both before and after the estimation of the forecast uncertainty. Such an approach allows the consideration of other requirements since it may be acceptable to trade off the quality of the forecast for increased lead time.

\subsection{Characterizing forecast uncertainty}

Acknowledging the uncertainty in forecasts of future output observations requires that both the sources of the uncertainty and their treatment in the forecasting process be recognized. This offers a starting point for the use of uncertainty representations within the frameworks used for flood response, such as CBEWS. A number of different sources of uncertainty are identified in Smith et al. (2013):

1. uncertainty in observed rainfall fields, only partially captured by interpolation of rain gauge data and calibration of radar data;

2. uncertainty in antecedent conditions, only partially captured by running hydrological models continuously;

3. uncertainty in calibration of model parameters, only partially captured by estimation of parameter distributions and their dependence on uncertainty in observations used in model calibration or data assimilation (which may be particularly high at flood levels);

4. uncertainty in model structures in representing runoff generation and routing processes. 
Table 1. Summaries of the model fit expressed in terms of the time-indexed observed values $\left(y_{t}\right)$, deterministic model output $\left(x_{t}\right)$ and realizations of the forecast distribution $\left(F_{t}\right)$ denoted $X_{t}$ and $X_{t}^{\prime}$.

\begin{tabular}{lll}
\hline Value & Formula & Description \\
\hline$R_{t}^{2}$ & $1-\frac{\sum_{t}\left(y_{t}-x_{t}\right)^{2}}{\sum_{t}\left(y_{t}-\bar{y}\right)^{2}}$ & $\begin{array}{l}\text { Fraction of the variance of the observed data explained. } \\
\text { Values approaching 1 are preferred. }\end{array}$ \\
\hline YIC & $\log \left(\sum_{i} \frac{\Sigma_{i, i}}{\theta_{i}^{2}}\right)+\log \left(1-\mathrm{R}_{t}^{2}\right)$ & $\begin{array}{l}\text { An information criteria that trades the identifiability of the } \\
\text { parameters (first term) with the model performance (second term). } \\
\text { On a log scale, more negative values are to be preferred. }\end{array}$ \\
\hline $\begin{array}{l}\text { Bayesian information } \\
\text { criteria (BIC) }\end{array}$ & $n \log \left(\sum_{t}\left(y_{t}-x_{t}\right)^{2}\right)+(k+n) \log (n)$ & $\begin{array}{l}\text { An information criteria offering an alternative trade off between } \\
\text { the number of parameters } k \text { and the fit to the } n \text { observation. The formula } \\
\text { given presumes independent and identically distributed errors. }\end{array}$ \\
\hline $\begin{array}{l}\text { Continuously ranked } \\
\text { probability score } \\
\text { (CRPS) }\end{array}$ & $\frac{1}{2} \mathrm{E}_{F_{t}}\left|X_{t}-X_{t}^{\prime}\right|+\mathrm{E}_{F_{t}}\left|X_{t}-y_{t}\right|$ & $\begin{array}{l}\text { An assessment of forecast performance on the same scale as } \\
\text { the observations, which is based on summaries of precision (first term) } \\
\text { and accuracy (second term). Corresponds to the mean absolute error in } \\
\text { the case of a deterministic forecast. }\end{array}$ \\
\hline
\end{tabular}

The first three of these sources are addressed in part through assimilation of observed water levels to correct the starting point (or initial states) of the model prior to generating new forecasts and in part through a non-parametric quantification of the forecast errors. The deductive method of model selection outlined in Sect. 5.2 allows for the exploration of the potential impact of uncertainty on the model structures, although in forecasting only one model structure is utilized.

Assimilating observations of the water level to improve the forecasts generated by the simplified DBM models can be considered as a special case of the more general state space framework for non-linear models (e.g. Liu and Gupta, 2007). Since the effective rainfall is computed from observed data, the uncertainty in the initial states of the model corresponds to the uncertainty in the output of each of the linear pathways of response. The evolution of these unknown states is governed by linear equations that may be embedded in the linear Kalman filter as a framework for assimilating new observations and producing probabilistic forecasts.

The assumptions of the linear Kalman filter, particularly those relating to the unbounded, hence potentially negative, values that may be taken by the output of the pathways of response, are inconsistent with the model formulation. Therefore, as in Smith et al. (2014), a two-stage process is used. Firstly, the noise variance ratios of the linear filter are selected to minimize the sum, over all lead times and time steps, of the squared errors of the expected forecast. Following this the expected value of the forecasts offered by the linear filtering are calibrated to the observed output using quantile regression. This handles the uncertainty arising from all the sources noted earlier and not accounted for by the data assimilation in a lumped fashion. A number of quantile regression techniques have been used in hydrology (see Weerts et al., 2011, and references within). In this work the quantile regression follows the non-parametric approach outlined in Yu (1999).

\subsection{Data requirements}

A further advantage of DBM modelling in the context of augmenting CBEWS is the relatively limited data required for their development. Table 2 outlines the typical data requirements for the construction of a DBM model representing a rainfall-water level relationship. Similar data periods are required for a model representing flood routing and using an observed upstream water level as input.

There is no requirement for physiographical information (such as a digital terrain model or land surface characteristics) beyond readily available metadata such as catchment maps showing rain gauges and river connectivity. Nor are further observations such as global radiation or wind speed required.

For low amounts of data, which are best considered on an event basis, it is suggested that estimation of the model be carried out using a cross-validation approach in which the performance of the model for each event is evaluated using parameters estimated from the remainder of the data. With larger data quantities the split sample approach where calibration and validation periods are chosen can be successfully used. The quantity and quality of available data will also influence the estimation of the forecast uncertainty. It should not be expected that high (or low) quantiles of the forecast uncertainty can be reliably estimated from small samples of data.

\section{Experimental application to the Karnali River basin}

Two experimental applications were undertaken, forecasting the water level at Chisapani using catchment-averaged rainfall derived from the three most reliable automated rain 
Table 2. Typical data requirements for the DBM methodology to be applied in a catchment (minimal data requirements in bold) (after Smith et al., 2013). Temperature only required if snow melt is a significant runoff generation mechanism (Smith et al., 2014).

\begin{tabular}{lll}
\hline Variable & Time step & Time period \\
\hline Precipitation & $15 \mathrm{~min}, \mathbf{1 ~ h}$ & $\mathbf{1 0}$ significant events, 5+ years \\
Discharge or water level & $15 \mathrm{~min}, \mathbf{1 ~ h}$ & $\mathbf{1 0}$ significant events including baseflow periods, 5+ years \\
Temperature & $15 \mathrm{~min}$, diurnal profile & $\mathbf{1 0}$ significant events, 5+ years \\
\hline
\end{tabular}

gauges (Chisapani, Dipayal and Asaraghat), which have been operational since 2011. Data on an hourly time step were used. As can be seen in Fig. 3, there may be significant missing or poor quality data outside of the monsoon period. The marked deviation between the rain gauge readings in Fig. 3 suggests a high degree of spatial patterning in the precipitation.

The two experiments mimic a plausible operational deployment. In the first experiment a forecasting model was estimated using data from 2011 and 2012 and was then used to predict the 2013 monsoon and flood. This provides a stern test since 2013 contains a flood event whose magnitude, approximately $14 \mathrm{~m}$, exceeds those in the calibration period by around $4 \mathrm{~m}$. In the second experiment, data from 2011 to 2013 were used to estimate the model and the 2014 flood, which peaked at over $16 \mathrm{~m}$ was forecast.

Currently in the Karnali River basin, an anticipatory warning is issued if the water level at the Chisapani gauge rises above $10 \mathrm{~m}$, with a danger warning (indicating the probability of severe flooding downstream) issued at $10.8 \mathrm{~m}$. The focus of these experiments was therefore not just on prediction of the peak magnitudes but also on when the forecasts indicate the crossing of these warning thresholds.

\subsection{Experiment 1}

The constant value relating to low water level conditions was estimated from the calibration data to be $3.07 \mathrm{~m}$. Table 3 shows the performance of a selection of the estimated models ranked by the YIC criteria. No models with three parallel pathways of response or with the sigmoid non-linearity are shown since these return a high YIC value due to the high level of uncertainty in the estimation of the parameters. The similarity of the $R_{t}^{2}$ and YIC values indicates that no individual model structure is, in terms of these criteria, superior to the others.

Visual inspection of the model hydrographs suggests that the models with two pathways of response $(n=2)$ capture the dynamics of the system markedly better those with only one. Regardless of the non-linearity, models with a time delay of greater then $6 \mathrm{~h}(d>6)$ appear to have poor correspondence to the rising limb of the hydrograph. This indicates that there is a significant response in the water level to the observed precipitation in at most $5 \mathrm{~h}$. Given this, a time delay of $5 \mathrm{~h}(d=5)$ was chosen to maximize the forecast lead time while retaining an acceptable fit.
Table 3. Summaries of the performance of a subset of models during the calibration period (1 April 2011-30 September 2012).

\begin{tabular}{|c|c|c|c|c|c|c|}
\hline Non-linearity & $n$ & $\begin{array}{c}d \\
{[\mathrm{~h}]}\end{array}$ & $R_{t}^{2}$ & $\begin{array}{c}\text { MAE } \\
{[\mathrm{m}]}\end{array}$ & $\mathrm{BIC}$ & YIC \\
\hline None & 2 & 8 & 0.802 & 0.506 & 34412.30 & -17.267 \\
\hline None & 2 & 8 & 0.802 & 0.506 & 34412.30 & -17.267 \\
\hline None & 2 & 7 & 0.802 & 0.622 & 34392.15 & -17.212 \\
\hline None & 2 & 6 & 0.802 & 0.620 & 34375.27 & -17.134 \\
\hline None & 2 & 5 & 0.803 & 0.616 & 34355.40 & -17.079 \\
\hline None & 2 & 4 & 0.803 & 0.613 & 34342.57 & -16.987 \\
\hline None & 2 & 3 & 0.803 & 0.610 & 34327.32 & -16.917 \\
\hline None & 2 & 2 & 0.803 & 0.606 & 34314.13 & -16.835 \\
\hline None & 2 & 1 & 0.804 & 0.603 & 34298.01 & -16.771 \\
\hline Power law & 2 & 9 & 0.828 & 0.481 & 32368.67 & -16.244 \\
\hline Power law & 2 & 8 & 0.828 & 0.480 & 32313.62 & -16.181 \\
\hline Power law & 2 & 7 & 0.829 & 0.480 & 32258.15 & -16.124 \\
\hline Power law & 2 & 6 & 0.830 & 0.480 & 32205.95 & -16.035 \\
\hline None & 1 & 2 & 0.800 & 0.499 & 34536.61 & -16.017 \\
\hline None & 1 & 3 & 0.800 & 0.499 & 34553.34 & -16.003 \\
\hline None & 1 & 5 & 0.799 & 0.500 & 34587.50 & -15.995 \\
\hline None & 1 & 8 & 0.798 & 0.500 & 34645.20 & -15.995 \\
\hline None & 1 & 7 & 0.799 & 0.500 & 34625.23 & -15.994 \\
\hline None & 1 & 6 & 0.799 & 0.500 & 34606.38 & -15.991 \\
\hline None & 1 & 9 & 0.798 & 0.500 & 34665.07 & -15.990 \\
\hline None & 1 & 1 & 0.800 & 0.499 & 34518.39 & -15.989 \\
\hline None & 1 & 4 & 0.800 & 0.500 & 34570.68 & -15.989 \\
\hline Power law & 2 & 5 & 0.830 & 0.479 & 32151.79 & -15.963 \\
\hline Power law & 2 & 4 & 0.831 & 0.479 & 32103.44 & -15.854 \\
\hline Power law & 2 & 3 & 0.831 & 0.478 & 32054.01 & -15.775 \\
\hline Power law & 2 & 2 & 0.832 & 0.478 & 32007.97 & -15.669 \\
\hline Power law & 2 & 1 & 0.833 & 0.478 & 31960.19 & -15.557 \\
\hline Power law & 1 & 9 & 0.815 & 0.501 & 33382.66 & -13.458 \\
\hline Power law & 1 & 8 & 0.816 & 0.500 & 33344.82 & -13.451 \\
\hline Power law & 1 & 7 & 0.816 & 0.500 & 33307.00 & -13.440 \\
\hline Power law & 1 & 6 & 0.817 & 0.500 & 33269.80 & -13.429 \\
\hline Power law & 1 & 5 & 0.817 & 0.499 & 33234.05 & -13.422 \\
\hline
\end{tabular}

Figure 5 shows the marked improvement that results from the use of data assimilation and the uncertainty representation. After data assimilation is applied, performance between the two models shown is very similar; however, due to its superior performance without data assimilation, particularly at high water levels (e.g. at a threshold of $8 \mathrm{~m}$ ), the model with the power law non-linearity is to be preferred.

With only a single flood event in the validation period of 1 June-30 September 2013, detailed analysis of model performances in forecasting the crossing of the warning 


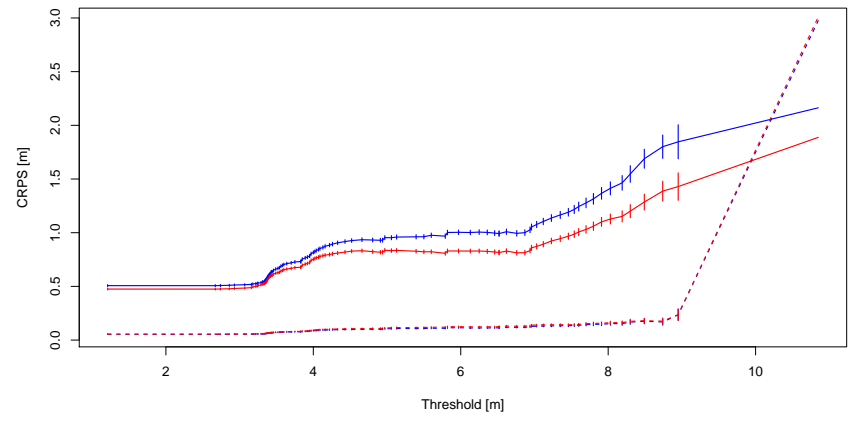

Figure 5. Summary plot of the CRPS results of two model fits. The lines correspond to the mean CRPS value evaluated based on the time steps for which the observed value exceeded the threshold shown on the $x$ axis. Where shown, the vertical error bars represent \pm 2 standard deviations of the mean estimate. The results of two pathway models with a $5 \mathrm{~h}$ time delay and with (red) or without (blue) the power law non-linearity are shown for both the estimated model (solid) and for the $5 \mathrm{~h}$ lead time forecasts (dashed).

levels is not possible. However, Fig. 6 issued at 16:00 LT 17 June 2013 shows that the model discriminates between exceedance and non-exceedance of the warning and danger thresholds, even at its maximum lead time.

\subsection{Experiment 2}

The analysis performed in Experiment 1 was repeated using a longer calibration period, 1 April 2011-1 September 2013. This contains data for a further monsoon period during which a flood event occurred. The impact of this on model estimation can be clearly seen in the results shown in Table 4 . In contrast to Table 3, there is a clear preference for model with $n=2$ and some preference for a power law non-linearity.

Taking, as in Experiment 1, the model with a power law non-linearity, $n=2$ and $d=5$ (with revised parameter estimates). Figure 7 shows the forecasts issued at 23:00 14 August 2014. Again the model clearly discriminates on the crossing of the warning thresholds.

\subsection{Summary of experiments}

The model and approach allows visual presentation of anticipated water level at Chisapani up to $5 \mathrm{~h}$ in the future, along with graphs of probability of reaching warning or danger level in each of the next $5 \mathrm{~h}$ (Figs. 6 and 7).

In the period 2011-2015 (the period for which reliable hourly observed data are available for the Karnali River basin) the danger level was crossed twice, at the two time steps shown in Figs. 6 and 7. For the two illustrated events, the forecast registers a greater than $80 \%$ probability of a warning level being reached. With such a high probability an advance warning would likely be triggered. Therefore, neither of these forecasts could be considered as missing the forthcoming event. There were no other cases in the avail-
Table 4. Summaries of the performance of a subset of models during the calibration period (1 April 2011-1 September 2013). This shows a clearer definition of the preferred model then results in Table 3 .

\begin{tabular}{lcccccc}
\hline Non-linearity & $n$ & $d$ & $R_{t}^{2}$ & $\begin{array}{c}\text { MAE } \\
{[\mathrm{m}]}\end{array}$ & BIC & YIC \\
\hline Power law & 2 & 2 & 0.807 & 0.549 & 39697.05 & -22.236 \\
Power law & 2 & 3 & 0.806 & 0.550 & 39804.56 & -22.202 \\
Power law & 2 & 1 & 0.808 & 0.548 & 39596.65 & -22.176 \\
Power law & 2 & 8 & 0.797 & 0.557 & 40504.23 & -22.161 \\
Power law & 2 & 9 & 0.796 & 0.558 & 40655.08 & -22.161 \\
Power law & 2 & 5 & 0.803 & 0.553 & 40056.37 & -22.134 \\
Power law & 2 & 4 & 0.804 & 0.551 & 39926.08 & -22.133 \\
Power law & 2 & 7 & 0.799 & 0.555 & 40349.75 & -22.114 \\
Power law & 2 & 6 & 0.801 & 0.554 & 40203.86 & -22.102 \\
None & 2 & 9 & 0.794 & 0.547 & 40796.81 & -21.719 \\
None & 2 & 8 & 0.795 & 0.547 & 40719.24 & -21.591 \\
None & 2 & 7 & 0.796 & 0.547 & 40639.45 & -21.450 \\
None & 2 & 6 & 0.797 & 0.547 & 40571.15 & -21.306 \\
None & 2 & 5 & 0.798 & 0.547 & 40492.91 & -21.167 \\
None & 2 & 4 & 0.798 & 0.547 & 40437.03 & -20.998 \\
None & 2 & 3 & 0.799 & 0.547 & 40382.34 & -20.855 \\
None & 2 & 2 & 0.799 & 0.546 & 40339.38 & -20.709 \\
None & 2 & 1 & 0.800 & 0.546 & 40298.90 & -20.502 \\
None & 1 & 6 & 0.779 & 0.541 & 41894.44 & -16.979 \\
None & 1 & 5 & 0.780 & 0.541 & 41833.68 & -16.975 \\
None & 1 & 7 & 0.779 & 0.541 & 41954.98 & -16.969 \\
None & 1 & 4 & 0.781 & 0.540 & 41776.89 & -16.964 \\
None & 1 & 8 & 0.778 & 0.542 & 42017.90 & -16.963 \\
None & 1 & 9 & 0.777 & 0.542 & 42080.51 & -16.960 \\
None & 1 & 3 & 0.782 & 0.540 & 41720.96 & -16.959 \\
\hline & & & & & &
\end{tabular}

able data sample where a forecast gave a greater than $50 \%$ probability of exceeding the warning threshold, suggesting no potential false alarms were found in this sample. However, the limited time period of data and low number of observed events means care should be taken in interpreting the level of discrimination between flood and non-flood events that may be available from the forecasts.

From Chisapani, it takes $2-3 \mathrm{~h}$ for flood waters to arrive at the first significant communities approximately $30 \mathrm{~km}$ downstream. The settlement at Chisapani itself is mostly set well above the river and has a low flood risk. A reliable, accurate forecast with $5 \mathrm{~h}$ lead time at Chisapani could then, when added to the $2-3 \mathrm{~h}$ lead time offered by the existing CBEWS, result in a warning with 7-8 $\mathrm{h}$ lead time in the most affected downstream communities. While this extension in lead time may appear short, it is significant both in minimizing the risk to life as well as in allowing the first steps to be taken in minimizing the risk to livelihoods.

\section{Incorporating forecasts in CBEWS}

Following from the two experimental applications, the operational use of the Karnali model was piloted (jointly with DHM) in the 2016 monsoon. During the 2016 monsoon, the 

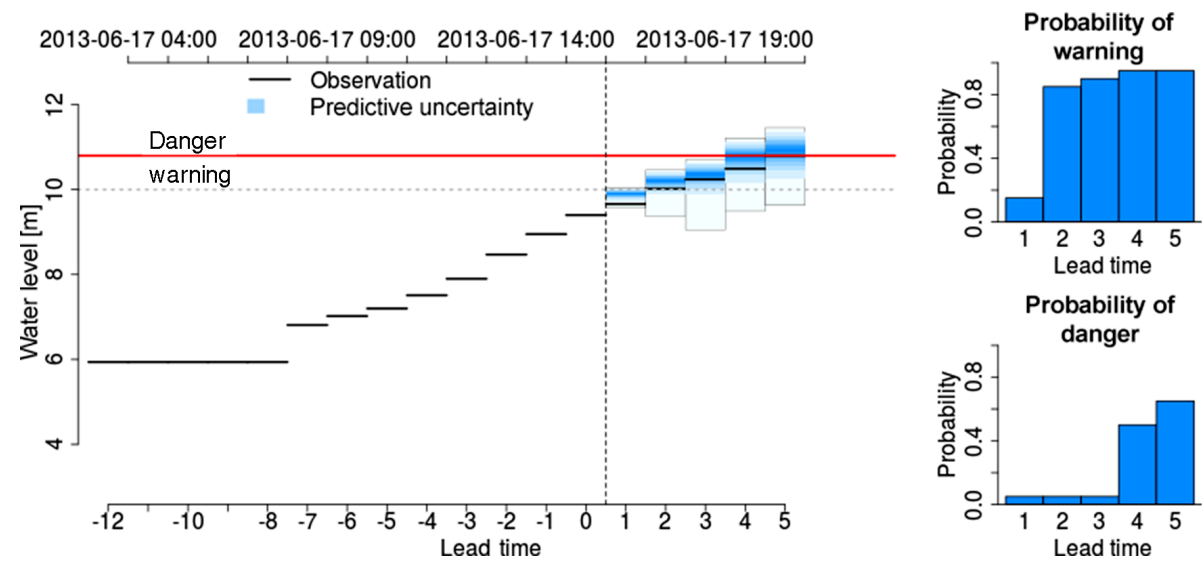

Figure 6. Forecast issued at 16:00 LT 17 June 2013. Shown on the left are the predictions of future water level (blue) and observed data (black). On the right the probability of crossing the respective warning levels at each lead time is shown.
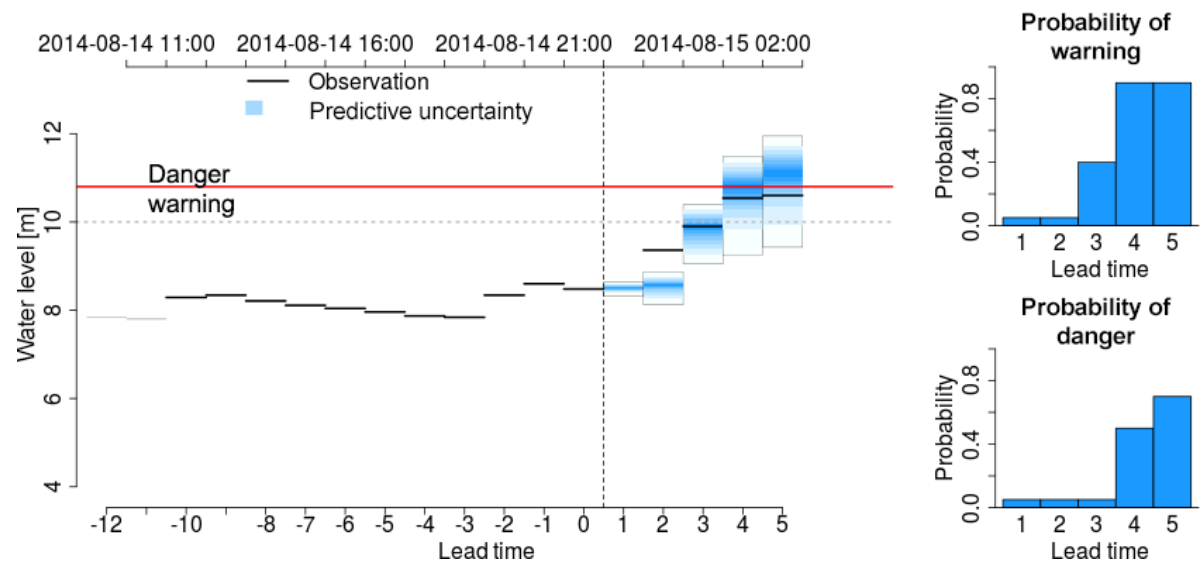

Figure 7. Forecast issued at 23:00 LT 14 August 2014 showing on the left the predictions of future water level (blue) and observed data (black). On the right the probability of crossing the respective warning levels at each lead time is shown.

water level for Karnali at Chisapani did not cross the warning and danger levels. Nevertheless, this pilot provided a unique opportunity to test the system in terms of retrieving realtime rainfall and river gauge data from stations across the Karnali River basin. Data assimilation and forecast quality were deemed satisfactory when compared with observed water level values. The system will continue to be maintained and evaluated in 2017.

Concurrently, DHM adopted and adapted the methodology presented in Sect. 5, taking it beyond the Karnali River basin to cover all the major basins of Nepal that flow from the mountains into the Terai plains (with reliable real-time data for 3-5 years). This includes large river basins such as the Narayani and Koshi, along with smaller basins, such as Kankai, Babai and West Rapti. Initial results indicate that the model provides an additional lead time of 3-5 $\mathrm{h}$ for larger basins and around 1-3 h for smaller basins. As part of this model development, DHM developed a methodology for deriving catchment-averaged precipitation values based on weights assigned to stations depending upon data quality, contribution of rainfall to runoff and proximity of the station to the flood forecasting point.

For the 2016 monsoon, the DHM adopted a top-down communication strategy for the trial probabilistic forecasts, whereby the DHM Central Office would provide advice to basin offices, which in turn would pass advice to district stakeholders including District Emergency Operation Centres (DEOC), security forces and community groups. These are well established communication channels on services manned 24/7 during the monsoon season.

It remains to be seen if such an approach to disseminating probabilistic forecast information is appropriate. In late 2016 Practical Action will consider best practices in the dissemination and communication of probabilistic forecasts within CBEWS. Lessons will be drawn from Bangladesh, where the Bangladesh Flood Forecasting and Warning Centre of the Bangladesh Water Development Board is disseminating 10day probabilistic flood forecasts to communities. It is hoped that a more direct approach to communicating probabilistic forecasts to communities will be attempted in future years. 
In 2017 Practical Action will also explore options for including rainfall forecast data in the model to generate further extensions in lead time. Considering how to effectively manage and communicate uncertainty in such forecasts will need to be a focus of future work.

\section{Conclusions}

This paper has outlined the current status of CBEWSs in Nepal, the benefits they have offered to communities that are vulnerable to flooding, as well as some ongoing challenges.

To address one of these challenges, that of limited lead time for warnings derived from observed data, a robust probabilistic forecasting methodology based on observed data has been proposed. Features that make this approach worth considering in the context of developing countries (and elsewhere) include

- near-zero running costs due to open free licensing, a simple and transferable means of interfacing with existing CBEWS infrastructure (including data collection, warning levels and dissemination mechanisms) and low computer hardware requirements. In an operational setting each new forecast and visualization, such as Fig. 7, can be generated in around $5 \mathrm{~s}$ on a basic single core Pentium PC.

- low data requirements. Like most hydrological approaches, there is the need for well-defined and consistent precipitation and river flow data, but unlike most approaches, direct use can be made of water level data. This removes the need to maintain a high-quality stagedischarge relationship for determining the discharge during flood events. Unlike many lumped or distributed modelling strategies, there is no need for detailed topographic, land use or soil property data or any reliance on external data providers. The timely transmission of gauged data, as well as a catalogue of historic data (see Sect. 5.4) is a prerequisite of a successful application.

- a particularly flexible framework. It can be used either as a lumped rainfall-runoff model (as outlined in the example) or for modelling river routing. The open and well-documented code may be maintained and developed with limited ongoing external support and restrictions.

- low human resource cost. Experience from providing training to Nepal DHM staff indicates that the modelling approach can be successfully taught over 12 days. Using the software tools developed by the authors, models can be constructed in a few hours on a standard laptop.
The case study presented indicates that for the CBEWS operating in the Karnali River basin the lead times at which warnings are issued can potentially be increased from the current $2-3 \mathrm{~h}$ to up to $7-8 \mathrm{~h}$. Subsequent work by DHM on other basins in Nepal indicates that similar increases in lead time are available elsewhere in the country. Achieving these increases will require strengthened connections between the probabilistic forecasts and other components of the CBEWS. Ongoing work is focused on this integration, appropriate ways to disseminate probabilistic forecasts and extending this approach to longer lead time forecasts.

\section{Data availability}

The data (Smith, 2017b) and software (Smith, 2017c) used in this work are available in publicly accessible repositories.

Author contributions. The paper was developed jointly by the authors, with PJS contributing the methodology in Sect. 5

Competing interests. The authors declare that they have no conflict of interest.

Acknowledgements. This work was initiated by stakeholders engaged in Early Warning Systems in Karnali who were looking for options to extend the lead time of warnings. Paul J. Smith was supported by the knowledge exchange placement funded by the NERC PURE initiative. Funding from the Zurich Flood Resilience Alliance also supported the work presented.

Edited by: R. Lamb

Reviewed by: E. M. Stephens and E. Coughlan de Perez

\section{References}

Alfieri, L., Smith, P. J., Thielen-del Pozo, J., and Beven, K. J.: A staggered approach to flash flood forecasting - case study in the Cévennes region, Adv. Geosci., 29, 13-20, doi:10.5194/adgeo29-13-2011, 2011

Baral, M.: Water Induced Disasters, Flood Hazard Mapping \& Koshi Flood Disaster of Nepal, in: Report prepared for East \& Southeast Asia Regional Seminar on Flood Hazard Mapping, 17-19 February 2009, Manila, Philippines, available at: http://www.icharm.pwri.go.jp/training/ 2009seminar/progressreport2009_nepal.pdf, last access: 10 January 2017, 2009.

Beven, K., Leedal, D., Smith, P., and Young, P.: Identification and representation of state dependent nonlinearities in flood forecasting using the DBM methodology, in: System identification, environmental modelling and control, Springer, 341-366, 2011.

Brown, S.: Science for Humanitarian Emergencies and Resilience (SHEAR) scoping study: Annex 3 - Early warning sys- 
tem and risk assessment case studies, Tech. rep., 53 pp., doi:10.12774/eod_cr.june2014.brown, 2014.

Cloke, H. and Pappenberger, F.: Ensemble flood forecasting: A review, J. Hydrol., 375, 613-626, doi:10.1016/j.jhydrol.2009.06.005, 2009.

DesInventar: http://www.desinventar.net/DesInventar/profiletab. jsp?countrycode $=n p l$, last access: 7 August 2015 .

Dixit, A.: Kosi Embankment Breach in Nepal: Need for a Paradigm Shift in Responding to Floods, Econ. Polit. Weekly, 44, 70-78, 2009.

Frewer, L. J., Howard, C., Hedderley, D., and Shepherd, R.: What Determines Trust in Information About Food-Related Risks? Underlying Psychological Constructs, Risk Anal., 16, 473-486, doi:10.1111/j.1539-6924.1996.tb01094.x, 1996.

Gautam, D. K. and Dulal, K.: Determination of Threshold Runoff for Flood Warning in Nepalese Rivers, Journal of Integrated Disaster Risk Management, 3, 125-136, doi:10.5595/idrim.2013.0061, 2013.

Gautam, D. K. and Phaiju, A. G.: Community Based Approach to Flood Early Warning in West Rapti River Basin of Nepal, Journal of Integrated Disaster Risk Management, 3, 155-169, doi:10.5595/idrim.2013.0060, 2013.

Hall, A. R. and Inoue, A.: The large sample behaviour of the generalized method of moments estimator in misspecified models, J. Econometrics, 114, 361-394, 2003.

IFRC: Early Warning Early Action: A Regional Guideline for Effective Engagement, International Federation of Red Cross and Red Crescent Societies, available at: http://www.preventionweb. net/files/16725_16725ewsguidelineinenglish1.pdf, last access: 10 January 2017, 2010.

IFRC: Community Early Warning Systems: Guiding Principles, International Federation of Red Cross and Red Crescent Societies, available at: http://www.ifrc.org/PageFiles/103323/ 1227800-IFRC-CEWS-Guiding-Principles-EN.pdf, last access: 10 January 2017, 2012.

Ihaka, R. and Gentleman, R.: R: A Language for Data Analysis and Graphics, J. Comput. Graph. Stat., 5, 299-314, doi:10.1080/10618600.1996.10474713, 1996.

Khanal, N. R., Mool, P. K., Shrestha, A. B., Rasul, G., Ghimire, P. K., Shrestha, R. B., and Joshi, S. P.: A comprehensive approach and methods for glacial lake outburst flood risk assessment, with examples from Nepal and the transboundary area, Int. J. Water Resour. D., 31, 219-237, doi:10.1080/07900627.2014.994116, 2015.

Kundzewicz, Z.: Floods: Lessons about early warning systems, in: Late Lessons from Early Warnings: Science, Precaution, Innovation, EEA Report No 1/2013, edited by: Gee, D., Grandjean, P., Hansen, S. F., Hove, S., MacGarvin, M., Martin, J., Nielsen, G., Quist, D., and Stanners, D., European Environment Agency, 347-368, doi:10.2800/73322, 2013.

Leedal, D., Weerts, A. H., Smith, P. J., and Beven, K. J.: Application of data-based mechanistic modelling for flood forecasting at multiple locations in the Eden catchment in the National Flood Forecasting System (England and Wales), Hydrol. Earth Syst. Sci., 17, 177-185, doi:10.5194/hess-17-177-2013, 2013.
Liu, Y. Q. and Gupta, H. V.: Uncertainty in hydrologic modeling: Toward an integrated data assimilation framework, Water Resour. Res., 43, W07401, doi:10.1029/2006WR005756, 2007.

Mercy Corps and Practical Action: Establishing Community Based Early Warning System: Practitioner's Handbook, Mercy Corps and Practical Action, available at: http://www.preventionweb. net/educational/view/19893, last access: 10 January 2017, 2010.

MoHA: Nepal National progress report on the implementation of the Hyogo Framework for Action (2013-2015), Ministry of Home Affairs (MoHA) Nepal, available at: http://www.preventionweb.net/english/professional/policies/v. php?id=41755, last access: 10 January 2017, 2015.

NCVST: Vulnerability through the eyes of the vulnerable: climate change induced uncertainties and Nepal's development predicaments, Institute for Social and Environmental Transition - Nepal (ISET-N) \& Institute for Social and Environmental Transition, Kathmandu \& Boulder, CO, available at: http://i-s-e-t.org/resources/major-program-reports/ vulnerability-through-the-eyes-of-vulnerable.html, last access: 10 January 2017, 2009.

Nepal, S., Flügel, W.-A., and Shrestha, A. B.: Upstreamdownstream linkages of hydrological processes in the Himalayan region, Ecological Processes, 3, 19, doi:10.1186/s13717-0140019-4, 2014.

Newey, W. K. and West, K. D.: A Simple Positive Semidefinite, Heteroskedasticity and Autocorrelation Consistent Covariance matrix, Econometrica, 55, 703-708, doi:10.2307/1913610, 1987.

NRRC: Disaster Risk Reduction in Nepal, Nepal Risk Reduction Consortium, available at: http://un.org.np/sites/default/files/ 2011-04-19-nrrc-background-brief.pdf, last access: 10 January 2017, 2011.

Penning-Rowsell, E., Potts, D., Reynard, N., Simm, J., Tapsell, S., Thorne, C., and Wheater, H.: The Pitt Review: lessons learned from the 2007 floods, Cabinet Office, UK Government, available at: http://webarchive.nationalarchives.gov.uk/20100807034701/ http://archive.cabinetoffice.gov.uk/pittreview/thepittreview/ final_report.html, last access: 10 January 2017, 2008.

Practical Action: Early Warning Saving Lives - Establishing Community Based Early Warning Systems in Nepal: Learning \& Experience 2002-2008, Practical Action, available at: https://practicalaction.org/file/region_nepal/ early-warning-saving-lives.pdf, last access: 10 January 2017, 2008.

Practical Action and Mercy Corps: Community based early warning systems in South and South East Asia, Practical Action and Mercy Corps, available at: http://flagship4.nrrc.org.np/sites/default/files/documents/ best-practice-learning-in-community-based-EWS.pdf, last access: 10 January 2017, 2012.

Regmi, S., Potty, J., Raju, P., and Dash, I.: Performance Evaluation of the Weather Research Forecast Model for Nepal, in: Workshop on weather forecasting and flood early warning system in Nepal, 8 April 2011, Kathmandu, 2011.

Romanowicz, R. J., Young, P. C., and Beven, K. J.: Data assimilation and adaptive forecasting of water levels in the river Severn catchment, United Kingdom, Water Resour. Res., 42, W06407, doi:10.1029/2005WR004373, 2006. 
Romanowicz, R. J., Young, P. C., Beven, K. J., and Pappenberger, F.: A data based mechanistic approach to nonlinear flood routing and adaptive flood level forecasting, Adv. Water Resour., 31, 10481056, 2008.

Sharma, C. K.: A Treatise on water resources of Nepal, Sangeeta Sharma, Kathmandu, 1997.

Shrestha, A., Shah, S., and Karim, R.: Resource manual on flash flood risk management, International Centre for Integrated Mountain Development, Kathmandu, available at: http: //lib.icimod.org/record/7891, last access: 10 January 2017, 2008.

Shrestha, M., Kafle, S., Gurung, M., Nibanupudi, H., Khadgi, V., and Rajkarnikar, S.: Flood early warning systems in Nepal: a gendered perspective, International Centre for Integrated Mountain Development, Kathmandu, Nepal, available at: http: //lib.icimod.org/record/29959/files/Flood_EWS.pdf, last access: 10 January 2017, 2014.

Shukla, Y. and Mall, B.: Enhancing Frontline Resilience: TransBorder Community Based Flood Early Warning System in India and Nepal, in: UNESCO Chair in Technologies for Development: From Innovation to Social Impact, available at: http://cooperation.epfl.ch/files/content/sites/cooperation/files/ Tech4Dev\%202016/1125-Shukla-SE08-DRR_Full\%20Paper. pdf, last access: 10 January 2017, 2016.

Smith, P.: FloodForT User Manual v0.9. waternumbers, Lancaster, doi:10.5281/zenodo.263485, 2017a.

Smith, P.: Data from the Karnali Basin, Nepal used in Smith et al. doi:10.5194/nhess-16-1-2016, Data set, Zenodo, doi:10.5281/zenodo.263295, 2017b.

Smith, P.: FloodForT software Smith et al. doi:10.5194/nhess-16-12016, Data set, Zenodo, doi:10.5281/zenodo.263297, 2017c.

Smith, P. J., Beven, K. J., Leedal, D., Weerts, A. H., and Young, P. C.: Testing probabilistic adaptive real-time flood forecasting models, Journal of Flood Risk Management, 7, 265-279, doi:10.1111/jfr3.12055, 2013.

Smith, P. J., Panziera, L., and Beven, K. J.: Forecasting flash floods using data-based mechanistic models and NORA radar rainfall forecasts, Hydrolog. Sci. J., 59, 1403-1417, doi:10.1080/02626667.2013.842647, 2014.

UN: Hyogo Framework for Action 2005-2015: Building the Resilience of Nations and Communities to Disasters, Resolution 2, World Conference on Disaster Reduction in Kobe, Japan, 18-22 January 2005, United Nations, available at: http://www.unisdr.org/2005/wcdr/intergover/official-doc/ L-docs/Final-report-conference.pdf, last access: 10 January 2017, 2005.

UN: Sendai Framework for Disaster Risk Reduction 2015-2030, Third UN World Conference in Sendai, Japan, 18 March 2015, United Nations, available at: http://www.preventionweb.net/files/ 43291_sendaiframeworkfordrren.pdf, last access: 10 January $2017,2015$.
UNISDR: Hyogo Framework for Action (HFA) 2005-2015, World Conference on Disaster Reduction Geneva, Switzerland, United Nations Inter-Agency Secretariat of the International Strategy for Disaster Reduction, available at: http://www.unisdr.org/2005/wcdr/intergover/official-doc/ L-docs/Hyogo-framework-for-action-english.pdf, last access: 10 January 2017, 2005.

UNISDR: Global Survey of Early Warning Systems: An Assessment of Capacities, Gaps and Opportunities towards Building a Comprehensive Global Early Warning System for all Natural Hazards, United Nations International Strategy for Disaster Reduction, Geneva, Switzerland, available at: http://www.unisdr.org/2006/ppew/info-resources/ewc3/ Global-Survey-of-Early-Warning-Systems.pdf, last access: 10 January 2017, 2006.

Weerts, A. H., Winsemius, H. C., and Verkade, J. S.: Estimation of predictive hydrological uncertainty using quantile regression: examples from the National Flood Forecasting System (England and Wales), Hydrol. Earth Syst. Sci., 15, 255-265, doi:10.5194/hess-15-255-2011, 2011.

WMO: Synthesis of the Status and Trends with the Development of Early Warning Systems. A Contribution to the Global Assessment Report 2015 (GAR15), Priority for Action (PFA) 2 - Core Indicator (CI) 3: Early Warning Systems are in Place for all Major Haza rds with Outreach to Communities, Background Paper prepared for the Global Assessment Report on Disaster Risk Reduction 2015, WMO, Geneva, available at: http://www.preventionweb.net/english/hyogo/gar/2015/ en/bgdocs/WMO,\%202014a.pdf, last access: 10 January 2017, 2015.

Young, P.: Top-down and data-based mechanistic modelling of rainfall-flow dynamics at the catchment scale, Hydrol. Process., 17, 2195-2217, 2003.

Young, P. C.: Advances in real-time flood forecasting, Philos. T. Roy. Soc. A, 360, 1433-1450, 2002.

Young, P. C. and Beven, K. J.: Data-Based Mechanistic Modeling And The Rainfall-Flow Nonlinearity, Environmetrics, 5, 335363, 1994.

$\mathrm{Yu}, \mathrm{K}$.: Smoothing regression qunatile by combining k-NN estimation with Local Linear Kernel fitting, Stat. Sinica, 9, 759-774, 1999.

Zurich: Risk Nexus: Urgent case for recovery: what we can learn from the August 2014 Karnali River floods in Nepal, available at: http://reliefweb.int/sites/reliefweb.int/files/resources/ risk-nexus-karnali-river-floods-nepal-july-2015.pdf, last access: 10 January 2017, 2015. 